\title{
Standards of Arm Muscle by Stature for the Assessment of Nutritional Status of Children
}

\author{
A.R. FRISANCHO AND D.P. TRACER \\ Center for Human Growth and Development and Department of \\ Anthropology, University of Michigan, Ann Arbor, Michigan 48108
}

\begin{abstract}
KEY WORDS Anthropometry, Muscle area, Growth, Height, Nutritional status
\end{abstract}

\begin{abstract}
This study is based on a sample of 9,134 children ranging in age from 2 to 17 years from which the excessively lean and fat children by skinfold thickness were excluded. This sample was derived from the combined data sets of the first and second National Health and Nutrition Examination Surveys (NHANES I and II) of 1971-1974 and 1976-1980. Means and percentiles of upper arm muscle area were calculated for $3 \mathrm{~cm}$ increments in stature from 84 to $184 \mathrm{~cm}$ for boys and from 84 to $176 \mathrm{~cm}$ for girls. Based on means, Zscore units, and percentile ranges of upper arm muscle area by stature, five operational categories of nutritional status have been established. It is recommended that these standards and this classification system be used to supplement current standards of weight for age and weight for height in order to obtain a more complete assessment of body composition and nutritional status.
\end{abstract}

Evaluations of growth and nutritional status are usually made with reference to 1 ) the growth curves of Stuart and Stevenson (1969), which were based on studies conducted during the 1950s of children from Boston and Iowa City, 2) the Tanner growth curves, based on investigations of British children (Tanner et al., 1965), 3) the Fels Research Institute growth curves (Hamill et al., 1977), based on studies of a longitudinal sample of 867 children evaluated during the period of 19291975, and 4) the National Center for Health Statistics (NCHS) growth curves, which were derived from a combined sample of data from the NCHS's Health Examination Surveys (HES), conducted during 1963-1965 and 1970-1974, and data from the Fels Research Institute (Hamill et al., 1977). A common feature of all these standards is that they provide information only on height and weight. Using these standards as reference, investigators have determined the extent to which children are either normal, advanced, or delayed in their growth for age. Furthermore, these standards are used to infer whether children are either obese or undernourished for their height (Waterlow et al., 1977). Although this approach has the advantage of being based on easily obtainable measure- ments, it is ineffective for accurately distinguishing the truly malnourished child from the simply underweight child. Protein-energy malnutrition (PEM) is characterized by a decrease in both fat and muscle tissue. Usually a child suffering from PEM will have a low weight for height, but a tall and normally lean child can also have a low weight for height. Similarly, because obesity is characterized by excess fat, an obese child usually has a high weight for height; but a muscular and large-framed child can also have a high weight for height. In other words, excess weight does not necessarily imply excess fat, and being underweight is not necessarily associated with PEM. For this reason, assessment of nutritional status based only on weight and height, especially when the degree of under- or overweight is moderate, is bound to be ineffective in distinguishing the truly wasted (i.e., low fat and muscle) from the normally low-weight child and the truly obese from the normally heavy child. Therefore, because of the lack of an appropriate anthropometric standard, evaluations of malnutrition are either grossly overesti-

Received June 4, 1986; revision accepted November 10, 1986. 
mated or underestimated (Dibley et al., 1985; Keller et al., 1983; Monteiro, 1985; Trowbridge, 1979). Thus there is a critical need for an anthropometric standard that permits the evaluation of growth and the components of over- and underweight and thus accurately determines the nutritional status of children. For this reason, we have developed means and percentiles of upper arm muscle area by height for children aged 2-17 years derived from the data sets of the first and second National Health and Nutritional Examination Surveys conducted during 19711974 and 1976-1980 (NHANES I and II).

\section{MATERIALS AND METHODS}

This study was based on a subsample selected from the combined data sets from NHANES I and II. The following sections give a general description of the NHANES samples and the procedure for selecting from this pool the desirable subsample utilized in the construction of the present standards.

\section{NHANES sample}

The combined cross-sectional sample of NHANES I and II includes 44,130 subjects aged 1-74 years. NHANES I was conducted by the NCHS according to a multistage, stratified sampling approach, which included 28,043 persons who represented the 194 million noninstitutionalized civilians aged 1-74 years of the United States. Of the 28,043 individuals who made up the sampling universe of NHANES I, 23,808 (84.9\%) were included in the present study. NHANES II was conducted by the NCHS following the same sampling and data collection methods as in NHANES I. The stratified probability sample included the selection of 27,801 persons aged 6 months to 74 years who represented the population of 196 million noninstitutionalized civilians in the United States. Of the 27,801 individuals who were the sampling universe of NHANES II, 20,322 (73.1\%) were interviewed and examined. Hence the present study includes a total sample of 44,130 $(23,808$ for NHANES I and 20,322 for NHANES II).

The distribution of the height and weight of the NHANES I subsample, when appropriately weighted for sampling variability, was indistinguishable from that of the NHANES II subsample. Similar results were found by Abraham et al. (1983) and Simopoulos and van Itallie (1984). For this reason, and in view of the critical need for a large sample size, we decided to merge the data of NHANES I and NHANES II, treating them as a single sample. To do so, we calculated a new sampling weight by dividing each subject's sampling weight by two as recommended by the NCHS. The mathematical derivation for this approach has been given elsewhere (Frisancho, 1984).

\section{Desirable subsample}

A general assumption in the evaluation of human growth and nutritional status is that the standard embodies desirable qualities that the individual or population aims to reach. In terms of nutritional status, it is now generally accepted that excessive fatness is associated with negative health risk factors (Hubert et al., 1983; Simopoulos and van Itallie, 1984). Similarly, excessive leanness is also associated with negative health risk factors (Andres, 1981; Blastow et al., 1983; Chandra, 1981; Garn et al., 1983). Therefore, to be considered desirable, an anthropometric standard should be based on individuals who are neither excessively fat nor excessively lean. Since the NHANES I and II data were obtained to derive representative samples of all segments of the U.S. population from the anthropometric point of view, it includes individuals with undesirable traits as well as those with desirable traits. Therefore, these anthropometric data cannot be used as standards, although they were used as such in previous investigations (Cronk and Roche, 1982; Frisancho, 1974, 1981, 1984; Hamill et al., 1977). For this reason, the present standards have been constructed excluding those individuals who were either excessively fat or excessively lean as evaluated by triceps and subscapular skinfold thicknesses.

With this purpose in mind, age- and sexspecific percentiles for triceps and subscapular thicknesses were established. Then, all those individuals whose triceps and subscapular skinfolds were either above the 85th or below the 2 nd age- and sex-specific percentiles were excluded from the sample. This procedure left a total sample of 9,134 desirable examinees ranging in age from 2 to 17 years. Analysis of some of the biomedical information indicated that the excluded obese individuals (above the 85th percentiles for triceps and subscapular skinfolds) were characterized by significantly higher blood pressures and elevated serum cholesterol compared to the nonobese sample (Frisancho, 
1986). This finding supports the notion that those individuals who are characterized by excessive fatness are also characterized by negative health risk factors.

\section{Anthropometric dimensions}

The study is based on measurements of stature, triceps skinfold thickness, and upper arm circumference, which will be briefly described below. A more complete description of the general protocol for obtaining anthropometric measurements is given elsewhere (Frisancho, 1986).

Stature: Stature was measured with the examinee wearing disposable foam-rubber slippers, feet together, back and heels against the upright bar of the stature scale, head approximately in the Frankfort horizontal plane ("look straight ahead") with some assistance and demonstration when necessary. The height-measuring equipment consisted of a vertical bar with a steel tape attached to a level platform. Attached perpendicularly to the vertical bar was a horizontal bar, which was brought down snugly on the examinee's head (Johnson et al., 1981).

Midupper arm circumference: The midupper arm circumference was measured to the nearest centimeter with a steel tape and the right arm hanging relaxed. The measurement was taken midway between the tip of the acromion and the olecranon process.

Triceps skinfold thickness: Triceps skinfold thickness was measured to the nearest millimeter with a Lange skinfold caliper having a pressure of $10 \mathrm{~g} \mathrm{~mm}^{2}$ of contact surface area. The measurement was taken over the triceps muscle and at the same previously marked point, located halfway between the elbow and the acromial process of the scapula, with the skinfold parallel to the longitudinal axis of the upper arm (Johnston et al., 1972; Malina et al., 1972).

Upper arm muscle: Calculations of upper arm muscle and fat areas are based on measurements of the upper arm circumference and triceps skinfolds. The technique of computing upper arm areas using brachium radiographic shadow was originally used by Best and Kuhl (1953) and Baker and associates (Baker et al., 1958, 1965; Frisancho and Garn, 1971), who assumed that the upper arm and its constituents are cylindrical. Since then, this approach has been applied to determine upper arm muscle and fat areas from measurements of upper arm circumference and skinfold thickness (Amador et al.,
1982; Arnhold, 1969; Anderson, 1975; Frisancho, 1974, 1984; Gurney and Jelliffe, 1973, Peña et al., 1979; Gonzales and Rodriguez; 1983). Because this technique assumes that the upper arm and its constituents are cylindrical, the corresponding areas of cross section are computed from the formula that yields the areas of a circle from its circumference. Letting $\mathrm{C}$ equal the circumference of the upper arm, the total upper arm area (TUA) is

$$
\operatorname{TUA}\left(\mathrm{cm}^{2}\right)=\frac{(\mathrm{C})^{2}}{(4 \times 3.1416)} .
$$

Similarly, letting Ts equal the triceps skinfold thickness, the upper arm muscle area (UMA) is

$$
\operatorname{UMA}\left(\mathrm{cm}^{2}\right)=\frac{(\mathrm{C}-\mathrm{Ts} \times 3.1416)^{2}}{(4 \times 3.1416)} .
$$

Arm muscle by stature: Previous studies have given information on anthropometric dimensions by age. However, when age is not known or is unrealiable, as is often the case in the developing world, these data are of limited utility. For this reason, the present standards give the UMA by every $3 \mathrm{~cm}$ of stature for boys and girls classified in two age groups: 1) 2-11 years and $12-17$ years for boys and 2) 2-10 years and 11-17 years for girls.

\section{RESUITS AND DISCUSSION}

Tables 1-4 present the standards of UMA by stature for boy and girls. From these data, it is evident that prepubescent girls at the same height category have about the same UMA as boys. During adolescence, however, boys have significantly greater muscle area by height than girls.

The validity of estimates of UMA as indicators of body muscle and body protein has been evaluated by several investigators. As measured by 24-hr creatinine excretion (among subjects ingesting a creatinine-free diet), UMA is linearly related to total body muscle (Heymsfield et al., 1982; Trowbridge et al., 1982; Furst et al., 1978). Furthermore, among postoperative patients or those suffering from cancer or other debilitating diseases, measurements of UMA are excellent indicators of the severity of protein malnutrition (Heymsfield et al., 1982). This is especially the case when the disease is associated with retention of body water or tumor 
TABLE 1. Standards of upper arm muscle area $\left(\mathrm{cm}^{2}\right)$ by height $(\mathrm{cm})$ of $2-11$-year-old boys

\begin{tabular}{|c|c|c|c|c|c|c|c|c|c|c|c|c|}
\hline \multirow{2}{*}{$\begin{array}{l}\text { Height } \\
\text { (cm) }\end{array}$} & \multirow[b]{2}{*}{$\mathrm{N}$} & \multirow[b]{2}{*}{ Mean } & \multirow[b]{2}{*}{ SD } & \multicolumn{9}{|c|}{ Percentiles } \\
\hline & & & & 5 & 10 & 15 & 25 & 50 & 75 & 85 & 90 & 95 \\
\hline $84-86$ & 54 & 13.5 & 2.0 & 10 & 11 & 11 & 12 & 13 & 15 & 16 & 16 & 17 \\
\hline $87-89$ & 121 & 13.4 & 2.3 & 10 & 11 & 11 & 12 & 13 & 15 & 16 & 17 & 17 \\
\hline $90-92$ & 150 & 13.9 & 2.2 & 10 & 11 & 12 & 12 & 14 & 15 & 16 & 16 & 17 \\
\hline $93-95$ & 218 & 14.7 & 3.7 & 11 & 12 & 12 & 13 & 14 & 16 & 17 & 17 & 18 \\
\hline $96-98$ & 232 & 14.9 & 2.8 & 12 & 12 & 13 & 14 & 15 & 16 & 17 & 17 & 18 \\
\hline 99-101 & 231 & 15.5 & 2.9 & 12 & 13 & 13 & 14 & 15 & 17 & 17 & 18 & 19 \\
\hline $102-104$ & 221 & 16.0 & 3.4 & 12 & 13 & 14 & 14 & 16 & 17 & 18 & 19 & 20 \\
\hline $105-107$ & 230 & 16.3 & 2.2 & 13 & 14 & 14 & 15 & 16 & 18 & 18 & 19 & 20 \\
\hline $108-110$ & 209 & 17.1 & 3.5 & 13 & 14 & 14 & 15 & 17 & 19 & 19 & 20 & 21 \\
\hline $111-113$ & 200 & 17.7 & 2.6 & 14 & 14 & 15 & 16 & 18 & 19 & 20 & 21 & 22 \\
\hline $114-116$ & 155 & 18.3 & 3.4 & 14 & 15 & 16 & 16 & 18 & 20 & 21 & 21 & 23 \\
\hline $117-119$ & 146 & 19.2 & 3.8 & 15 & 16 & 16 & 17 & 19 & 21 & 22 & 23 & 24 \\
\hline $120-122$ & 129 & 19.7 & 3.5 & 15 & 16 & 17 & 18 & 19 & 21 & 22 & 23 & 24 \\
\hline $123-125$ & 133 & 20.8 & 4.1 & 16 & 17 & 18 & 19 & 20 & 23 & 24 & 25 & 26 \\
\hline $126-128$ & 132 & 22.0 & 4.7 & 17 & 19 & 19 & 20 & 22 & 23 & 25 & 25 & 26 \\
\hline $129-131$ & 128 & 21.9 & 3.4 & 17 & 18 & 18 & 19 & 22 & 24 & 25 & 26 & 27 \\
\hline $132-134$ & 134 & 23.2 & 3.5 & 18 & 19 & 20 & 21 & 23 & 25 & 26 & 27 & 29 \\
\hline 135-137 & 120 & 23.9 & 3.6 & 19 & 20 & 21 & 21 & 23 & 26 & 28 & 29 & 30 \\
\hline $138-140$ & 117 & 25.2 & 5.1 & 19 & 20 & 21 & 22 & 24 & 27 & 29 & 30 & 33 \\
\hline $141-143$ & 112 & 27.1 & 5.0 & 22 & 23 & 23 & 25 & 26 & 29 & 31 & 31 & 33 \\
\hline $144-146$ & 83 & 27.8 & 3.9 & 22 & 23 & 24 & 25 & 27 & 31 & 32 & 33 & 34 \\
\hline
\end{tabular}

TABLE 2. Standard of upper arm muscle area $\left(\mathrm{cm}^{2}\right)$ by height $(\mathrm{cm})$ of 2-10-year-old girls

\begin{tabular}{|c|c|c|c|c|c|c|c|c|c|c|c|c|}
\hline \multirow{2}{*}{$\begin{array}{l}\text { Height } \\
\text { (cm) }\end{array}$} & \multirow[b]{2}{*}{$\mathrm{N}$} & \multirow[b]{2}{*}{ Mean } & \multirow[b]{2}{*}{ SD } & \multicolumn{9}{|c|}{ Percentiles } \\
\hline & & & & 5 & 10 & 15 & 25 & 50 & 75 & 85 & 90 & 95 \\
\hline $84-86$ & 81 & 13.1 & 2.0 & 10 & 11 & 11 & 11 & 13 & 14 & 15 & 15 & 16 \\
\hline $87-89$ & 110 & 12.9 & 1.9 & 10 & 11 & 11 & 11 & 13 & 14 & 15 & 15 & 16 \\
\hline $90-92$ & 180 & 13.3 & 2.1 & 10 & 11 & 11 & 12 & 13 & 15 & 15 & 16 & 17 \\
\hline $93-95$ & 200 & 13.6 & 2.0 & 10 & 11 & 12 & 12 & 14 & 15 & 16 & 16 & 17 \\
\hline $96-98$ & 208 & 14.5 & 2.1 & 11 & 12 & 12 & 13 & 14 & 16 & 17 & 17 & 18 \\
\hline $99-101$ & 196 & 14.6 & 2.1 & 11 & 12 & 12 & 13 & 14 & 16 & 17 & 17 & 18 \\
\hline $102-104$ & 213 & 14.9 & 2.4 & 11 & 12 & 12 & 13 & 15 & 16 & 18 & 18 & 19 \\
\hline $105-107$ & 203 & 15.7 & 2.2 & 13 & 13 & 14 & 14 & 16 & 17 & 18 & 19 & 19 \\
\hline $108-110$ & 224 & 16.2 & 3.0 & 12 & 13 & 14 & 14 & 16 & 17 & 19 & 20 & 21 \\
\hline $111-113$ & 199 & 16.6 & 2.4 & 13 & 14 & 14 & 15 & 16 & 18 & 19 & 19 & 20 \\
\hline $114-116$ & 159 & 17.2 & 2.8 & 13 & 14 & 15 & 15 & 17 & 19 & 20 & 21 & 23 \\
\hline $117-119$ & 140 & 17.5 & 2.3 & 14 & 15 & 15 & 16 & 17 & 19 & 20 & 20 & 22 \\
\hline $120-122$ & 144 & 18.4 & 2.8 & 14 & 15 & 16 & 17 & 18 & 20 & 21 & 22 & 23 \\
\hline $123-125$ & 122 & 20.2 & 5.8 & 15 & 16 & 16 & 17 & 19 & 22 & 23 & 24 & 25 \\
\hline $126-128$ & 126 & 19.5 & 2.9 & 16 & 16 & 17 & 18 & 19 & 21 & 22 & 23 & 24 \\
\hline $129-131$ & 112 & 20.9 & 4.1 & 16 & 17 & 17 & 18 & 20 & 23 & 24 & 24 & 26 \\
\hline $132-134$ & 106 & 21.9 & 4.3 & 17 & 18 & 18 & 19 & 21 & 24 & 25 & 26 & 29 \\
\hline $135-137$ & 102 & 22.2 & 3.8 & 17 & 18 & 19 & 20 & 22 & 24 & 26 & 27 & 29 \\
\hline $138-140$ & 87 & 23.5 & 3.3 & 18 & 19 & 20 & 21 & 23 & 26 & 27 & 28 & 29 \\
\hline $141-143$ & 74 & 23.5 & 4.0 & 17 & 19 & 20 & 21 & 24 & 27 & 27 & 28 & 31 \\
\hline $144-146$ & 44 & 25.6 & 6.3 & 19 & 20 & 21 & 22 & 25 & 28 & 31 & 31 & 33 \\
\hline
\end{tabular}


TABLE 3. Standards of upper arm muscle arm $\left(\mathrm{cm}^{2}\right)$ by height $(\mathrm{cm})$ of 12-17-year-old boys

\begin{tabular}{|c|c|c|c|c|c|c|c|c|c|c|c|c|}
\hline \multirow{2}{*}{$\begin{array}{l}\text { Height } \\
\text { (cm) }\end{array}$} & \multirow[b]{2}{*}{$\mathrm{N}$} & \multirow[b]{2}{*}{ Mean } & \multirow[b]{2}{*}{$\mathrm{SD}$} & \multicolumn{9}{|c|}{ Percentile } \\
\hline & & & & 5 & 10 & 15 & 25 & 50 & 75 & 85 & 90 & 95 \\
\hline $144-146$ & 48 & 28.6 & 4.1 & 23 & 24 & 25 & 26 & 28 & 31 & 33 & 35 & 36 \\
\hline $147-149$ & 57 & 30.6 & 6.0 & 22 & 24 & 26 & 28 & 30 & 33 & 34 & 37 & 41 \\
\hline $150-152$ & 77 & 31.0 & 5.5 & 23 & 25 & 26 & 27 & 29 & 35 & 36 & 38 & 41 \\
\hline $153-155$ & 77 & 34.7 & 9.0 & 23 & 27 & 27 & 28 & 34 & 38 & 42 & 46 & 48 \\
\hline $156-158$ & 85 & 35.0 & 5.8 & 27 & 29 & 29 & 30 & 34 & 39 & 41 & 42 & 45 \\
\hline $159-161$ & 103 & 37.2 & 7.5 & 27 & 29 & 30 & 32 & 37 & 41 & 44 & 45 & 47 \\
\hline $162-164$ & 132 & 43.6 & 9.3 & 30 & 33 & 34 & 37 & 43 & 48 & 52 & 56 & 59 \\
\hline $165-167$ & 145 & 44.7 & 8.7 & 33 & 35 & 36 & 39 & 44 & 50 & 54 & 56 & 61 \\
\hline $168-170$ & 178 & 47.4 & 9.8 & 33 & 36 & 38 & 40 & 47 & 53 & 56 & 62 & 68 \\
\hline 171-173 & 181 & 48.8 & 9.0 & 36 & 38 & 40 & 42 & 48 & 54 & 57 & 60 & 64 \\
\hline $174-176$ & 143 & 51.2 & 8.9 & 38 & 41 & 42 & 44 & 52 & 58 & 60 & 63 & 64 \\
\hline $177-179$ & 131 & 50.7 & 8.9 & 37 & 41 & 42 & 45 & 50 & 54 & 59 & 61 & 71 \\
\hline $180-182$ & 73 & 53.9 & 10.7 & 41 & 41 & 42 & 45 & 55 & 59 & 65 & 68 & 74 \\
\hline
\end{tabular}

TABLE 4. Standards of upper arm muscle area $\left(\mathrm{cm}^{2}\right)$ by height $(\mathrm{cm})$ of 11-17-year-old girls

\begin{tabular}{|c|c|c|c|c|c|c|c|c|c|c|c|c|}
\hline \multirow{2}{*}{$\begin{array}{l}\text { Height } \\
\text { (cm) }\end{array}$} & \multirow[b]{2}{*}{$\mathrm{N}$} & \multirow[b]{2}{*}{ Mean } & \multirow[b]{2}{*}{$\mathrm{SD}$} & \multicolumn{9}{|c|}{ Percentiles } \\
\hline & & & & 5 & 10 & 15 & 25 & 50 & 75 & 85 & 90 & 95 \\
\hline 141-143 & 40 & 23.9 & 3.6 & 18 & 19 & 20 & 21 & 23 & 26 & 28 & 29 & 30 \\
\hline $144-146$ & 51 & 25.5 & 4.3 & 20 & 21 & 21 & 22 & 25 & 28 & 30 & 31 & 34 \\
\hline $147-149$ & 95 & 28.4 & 6.0 & 20 & 21 & 22 & 24 & 28 & 32 & 34 & 37 & 38 \\
\hline $150-152$ & 127 & 28.2 & 5.1 & 21 & 22 & 23 & 24 & 27 & 32 & 33 & 34 & 38 \\
\hline $153-155$ & 180 & 30.6 & 6.0 & 22 & 24 & 25 & 27 & 30 & 34 & 36 & 38 & 40 \\
\hline $156-158$ & 250 & 31.1 & 5.8 & 23 & 25 & 26 & 27 & 31 & 34 & 37 & 38 & 41 \\
\hline $159-161$ & 286 & 32.7 & 7.0 & 24 & 26 & 27 & 29 & 32 & 36 & 38 & 41 & 45 \\
\hline $162-164$ & 255 & 33.5 & 5.8 & 25 & 27 & 28 & 30 & 33 & 37 & 39 & 40 & 44 \\
\hline $165-167$ & 193 & 33.6 & 7.2 & 25 & 27 & 27 & 29 & 33 & 37 & 40 & 41 & 44 \\
\hline $168-170$ & 92 & 34.1 & 6.9 & 26 & 27 & 28 & 30 & 33 & 37 & 39 & 40 & 47 \\
\hline $171-173$ & 51 & 35.3 & 6.0 & 26 & 29 & 30 & 31 & 34 & 38 & 41 & 43 & 47 \\
\hline $174-176$ & 30 & 35.6 & 5.5 & 29 & 29 & 30 & 31 & 35 & 41 & 42 & 42 & 44 \\
\hline
\end{tabular}

TABLE 5. Anthropometric classification for the evaluation of nutritional status based on age and sex-specific anthropometric distributions*

\begin{tabular}{|c|c|c|c|c|}
\hline \multicolumn{2}{|c|}{ Statistical criteria } & \multicolumn{3}{|c|}{ By age and sex-specific criteria } \\
\hline Percentile & Z-score & $\begin{array}{l}\text { Height } \\
\text { for age }\end{array}$ & $\begin{array}{c}\text { Weight } \\
\text { for height }\end{array}$ & $\begin{array}{c}\text { Muscle area } \\
\text { for height }\end{array}$ \\
\hline $\begin{array}{l}0.0-5.0 \text { th } \\
5.1-15.0 \text { th } \\
15.1-85.0 \text { th } \\
85.1-95.0 \text { th } \\
95.1-100.0 \text { th }\end{array}$ & $\begin{array}{l}Z<-1.6 \\
-1.6 \leqslant Z<-1.0 \\
-1.0 \leqslant Z<+1.0 \\
+1.0 \leqslant Z<+1.6 \\
Z \geqslant+1.6\end{array}$ & $\begin{array}{l}\text { Stunted } \\
\text { Below average } \\
\text { Average } \\
\text { Above average } \\
\text { Advanced } \\
\end{array}$ & $\begin{array}{l}\text { Wasted } \\
\text { Below average } \\
\text { Average } \\
\text { Above average } \\
\text { Heavy } \\
\end{array}$ & $\begin{array}{l}\text { Wasted } \\
\text { Below average } \\
\text { Average } \\
\text { Above average } \\
\text { High muscle } \\
\end{array}$ \\
\hline
\end{tabular}

growth. Under such conditions, body weight may actually be above the reference standard, but clinically the patient may be undernourished. In this case, measurements of fat-free mass and total body protein would not provide an accurate indication of the severity of protein malnutrition, because both would include the tumor's protein and mass (Heymsfield et al., 1982). For these reasons, measurements of UMA are a more reliable index of PEM in such cases than are measurements of fat free mass or total body protein.

Various approaches have been used to evaluate the growth and nutritional status of children and adults. The usual approach has been to use percent of median as an indicator of the nutritional status of children. Gomez et al. (1956), using as a reference the 50th percentile of the Stuart and Stevenson (1969) 
weight for age values, set four categories of nutritional status: 1 ) normal (>90\% of the median), 2) first-degree malnutrition or mild malnutrition (76-90\% of median), 3) seconddegree malnutrition or moderate malnutrition (61-75\% of median), and 4) third-degree malnutrition or severe malnutrition $(<60 \%$ of the median). Since this method does not take into account the variability in the relative width of the distribution of weight for age indicators, a given percent of the median of weight for age does not have the same meaning across ages (Waterlow et al., 1977). For example, $60 \%$ of the median weight for age indicates a much more severe state of malnutrition in infants than in school-age children.

To overcome this difficulty, Waterlow et al. (1977) recommended that classifications of weight for height and height for age be expressed as multiples of the SD of the reference population rather than as percentages of the median. This method, which is known as the Z-score method, permits anthropometric cut-off points to be defined by extrapolation beyond the observed outer percentiles of the original reference data. For this reason, in our present study, we used this approach to establish five anthropometric categories of nutritional status. These five categories were based on both SD units and percentile ranges of UMA by stature, as follows.

1. Category $I=0-5$ th percentile or Z-score is less than -1.6 (i.e., $\mathrm{Z}<-1.6$ ).

2. Category $I I=5.1-15$ th percentile or $\mathrm{Z}$ score is between -1.6 and -1.0 (i.e., $-1.6 \leqslant \mathrm{Z}<-1.0$ ).

3. Category III $=15.1-85$ th percentile or Zscore is between -1.0 and +1.0 (i.e., $-1.0 \leqslant \mathrm{Z}<+1.0$ ).

4. Category IV $=85.1-95$ th percentile or $\mathrm{Z}$. score is between +1.0 and +1.6 (i.e., $-1.0 \leqslant \mathrm{Z}<+1.6)$.

5. Category $\mathrm{V}=95.1-100$ th percentile or $\mathrm{Z}$ score is equal to or greater than +1.6 (i.e., $\mathrm{Z} \geqslant+1.6$ ).

Table 5 presents these five categories with reference to the Waterlow et al. (1977) classification of height by age and weight by height along with the classification of muscle area by stature derived in the present study. Since the cut-off points are comparable across anthropometric dimensions and across all ages, the evaluation of nutritional status using this approach is not affected by the absolute size of the variable. For example, when a child whose weight by height is below the 5 th percentile and also possesses a muscle area by stature below the 5 th percentile, it can be inferred that the child is at risk of undernutrition or is truly wasted. A basic biological principle is that the organism's response to malnutrition follows a hierarchical sequence in which the nutritionally labile tissues, such as fat and muscle, are depleted first and, as malnutrition continues (in the case of chil. dren), growth in stature is retarded, which in turn may lead to stunting. The present clas. sification can be used to account for this process and yet still evaluate the severity and magnitude of protein calorie malnutrition. Thus, if both the stature and the UMA of a child are below the 5th percentile, or $1.6 \mathrm{Z}$ score units below the mean, this indicates a growth retardation associated with chronic undernutrition.

Therefore, it is recommended that these standards be used in conjunction with the weight for height tables to obtain a more complete evaluation of body composition and growth and hence nutritional status. By nature, any classification is arbitrary, and ultimately the utility of the proposed standards and classification system will be evident in term of their ability to predict morbidity or mortality outcomes.

\section{ACKNOWLEDGMENTS}

This research was supported in part by the Mead Johnson Nutritional Division, the Weight Watchers Foundation, and Health Products of Ann Arbor.

\section{LITERATURE CITED}

Abraham, S, Carroll, MD, Najjar, MF, and Fulwood, R (1983) Obese and overweight adults in the United States. Vital and Health Statistics, Series 11, No. 230, Hyattsville, MD: National Center for Health Statistics. DHHS Publ. No. PHS 83-1680.

Amador, M, Gonzales, ME, Cordova, L, and Perez, N (1982) Diagnosing and misdiagnosing malnutrition. Acta Paediatr. Acad. Sci. Hungaricae 23:391-401.

Anderson, MA (1975) Use of height-arm circumference measurement for nutritional selectivity in Sri Lanka school feeding. Am. J. Clin. Nutr. 28:775-781.

Andres, R (1981) Aging, diabetes and obesity. Mt. Sinai J. Med. 48:489-495.

Arnhold, R (1969) The QUAC stick: A field measure used by the Quaker service team, Nigeria. J. Trop. Pediatr. 15:241-247. 
Baker, PT, Frisancho, AR, and Thomas, RB (1965) A preliminary analysis of human growth in the Peruvian Andes. In MS Malhotra (ed.) Human Adaptability to Environments and Physical Fitness. Defense Institute of Physiology and Allied Sciences, Madras-3, Research and Development Organization, Ministry of Defense, Government of India, pp. 259-269.

Baker, PT, Hunt, EE Jr, and Sen, T (1958) The growth and interrelations of skinfolds and brachial tissues in man. Am. J. Phys. Anthropol. 16:39-58.

Behnke, AR, Feen, BG, and Welham, WC (1942) The specific gravity of healthy men. JAMA 118:495-499.

Best, WR, and Kuhl, WJ (1953) Estimation of Active Protoplasmic Mass by Physical and Roentgenological Anthropometry. Medical Nutrition Laboratory Report No. 114, Surgeon General's Department, U.S. Army.

Blastow, MD, Rawlings, J, and Allison, SP (1983) Undernutrition, hypothermia and injury in elderly women with fractured femur: An injury response to altered metabolism? Lancet 1:143-145.

Chandra, RK (1981) Immunodeficiency in undernutrition and overnutrition. Nutr. Rev. 39:225-231.

Cronk, CE, and Roche, AF (1982) Race- and sex-specific reference data for triceps and subscapular skinfolds and weight/stature. Am J Clin. Nutr. 35:335-347.

Dibley, MJ, Staehling, N, Nieburg, P, Trowbridge, FL (1985) Pitfalls in the interpretation of weight-forheight. XII International Congress of Nutrition, Brighton, U.K. (abstract).

Frisancho, AR (1974) Triceps skinfold and upper arm muscle size norms for assessment of nutritional status. Am. J. Clin. Nutr. 27:1052-1057.

Frisancho, AR (1981) New norms of upper limb fat and muscle areas for assessment of nutritional status. Am. J. Clin. Nutr. 34:2540-2545.

Frisancho, AR (1984) New standards of weight and body composition by frame size and height for assessment of nutritional status of adults and elderly. Am. J. Clin. Nutr. 40:808-819.

Frisancho, AR (1986) Anthropometric Standards for the Evaluation of Growth and Nutritional Status of Children and Adults. Health Products, Ann Arbor, MI 48104.

Frisancho, AR, and Garn, SM (1971) Skinfold thickness and muscle size: implications for developmental status and nutritional evaluation of children from Honduras. Am. J. Clin. Nutr. 24:541-546.

Furst, P, Bergstrom, J, Vinnars, E, Schildt, B, and Holstrom B (1978) Intracellular amino acids and energy metabolism in catabolic patients with regard to muscle tissue. In I. Johnston (ed.): Advances in Parenteral Nutrition. Lancaster, PA: M.T.P. Press pp. 85-104.

Garn, SM, Hawthorne, SV, Pilkington, JJ, and Pesick, SD (1983) Fatness and mortality in the west of Scotland. Am. J. Clin. Nutr. 38:313-319.

Gomez, F, Galvan, RR, Frenk, S, Munoz, JC, Chavez, R, Vasquez, J (1956) Mortality in second and third degree malnutrition. J. Trop. Pediatr. 2:77-83.

Gonzales, ME, and Rodriguez, C (1983) Estudio de algunos indicadores anthropometricos y funcionales en varones de 11-20 años. Rev. Cubana Pediatr. 55:644-660.

Gurney, TM, and Jelliffe, DB (1973) Arm anthropometry in nutritional assessment: Nomogram for rapid calcu- lation of muscle circumference and cross-sectional muscle and fat areas. Am. J. Clin. Nutr. 26:912-915.

Hamill, PV, Drizd, TA, Johnson, CL, Reed, RB, and Roche, AF (1977) NCHS growth curves for children, birth-18 years, United States. Vital and Health Statistics, Series 11, No 165, Hyattsville, MD: National Center for Health Statistics. DHEW Publ. No. PHS 781650 .

Heymsfield, SB, McManus, C, Smith, J, Stevens, V, and Nixon, DW (1982) Anthropometric measurement of muscle mass: Revised equations for calculating bonefree arm muscle area. Am. J. Clin. Nutr. 36:680-690.

Hill, GL, Blackett, RL, Pickford, I, Burkinshaw, L, Young, GA, Warren, JV, Schorah, CJ, and Morgan, DB (1977) Malnutrition in surgical patients. Lancet 1:689.

Hubert, HB, Feinleib, M, and McNamara, PM (1983) Obesity as an independent risk factor for cardiovascular disease: A 26-year follow up of participants in the Framingham Heart Study. Circulation 67:968-977.

Johnson, CL, Fulwood, R, Abraham, S, and Bryner, JD (1981) Basic data on anthropometric measurements and angular measurements of the hip and knee joints for selected age groups 1-74 years of age. United States, 1971-1975. Vital and Health Statistics, Series 11, No. 219, Hyattsville, MD: National Center for Health Statistics, 1981. DHEW Publ. No. PHS 81-1669.

Johnston, FE, Hamill, PVV, and Lemeshow, S (1972) Skinfold thicknesses of children 6-11 years, United States. Vital and Health Statistics, Series 11, No 120, Washington, DC: U.S.D.H.H.S.

Keller, W, and Filmore, CM (1983) Prevalence of proteinenergy malnutrition. World Health Statist. Quart. 36:129-167.

Malina, RM, Hamill, PVV, and Lemeshow, S (1972) Selected body measurements of children 6-11 years. United States Vital and Health Statistics, Series 11, No. 123, Washington, DC: U.S.D.H.H.S.

Monteiro, CA (1985) A critical assessment of recently proposed changes in anthropometric evaluation of nutritional status of children. XIII International Congress of Nutrition, Brighton, U.K. (abstract).

Peña, M, Barta, L, Regoly-Merei, A, and Tichy, M (1979) Anthropometric considerations regarding obese children. Acta Sei. Hung. 20:333-336.

Simopoulos, AP, and van Itallie, TB (1984) Body weight, health, and longevity. Ann. Intern. Med. 100:285-295.

Stuart, HC, and Stevenson, SS (1969) Growth and development. In WE Nelson (ed): Textbook of Pediatrics, 9th ed. Philadelphia: W.B. Saunders.

Tanner, JM, Whitehouse, RH, and Takaishi, M (1965) Standards from birth to maturity for height, weight, height velocity, and weight velocity: British children. Arch. Dis. Child. 41:454-464.

Trowbridge, FL (1979) Clinical and biochemical characteristics associated with anthropometric nutritional categories. Am. J. Clin. Nutr. 32:758-766.

Trowbridge, FL, Hiner, CD, and Robertson, AD (1982) Arm muscle indicators and creatinine excretion in children. Am. J. Clin. Nutr. 36:691-696.

Waterlow, JC, Buzina, R, Keller, W, Lane, JM, and Ni chamon, MZ (1977) The presentation and use of height and weight data for comparing the nutritional status of groups of children under the age of 10 years. Bull. WHO $55: 489-498$. 